\title{
Neopythagoreanism in the work of Johannes Kepler ${ }^{1}$
}

\author{
Carlos Alberto Cardona \\ Universidad Del Rosario - Escuela de Ciencias Humanas \\ Carrera 6 No. 12 C 16, oficina 506 Bogota N. A. 110231210 \\ Colombia \\ carloscardona1959@gmail.com
}

Article info

CDD: 521.3

Received: 21.10.2016; Revised: 00.00.0000; Accepted: 22.10.2016

DOI: http://dx.doi.org/10.1590/0100-6045.2016.V39N3.CS

Keywords:

Harmony

Analogy

Control Instrument

Limit

Pythagoras

\section{ABSTRACT}

In this article I argue that the methodology in the Johannes Kepler's work is guided by two principles of Pythagorean nature, they are: (i) sameness is made known by sameness, and (ii) harmony arises from establishing a limit to what is unlimited. By way of hypothesis, I present a general outline, which includes those principles, and I indicate how they are present in Kepler's investigations. I examine two particular cases in the light of that schema.

The importance given to geometry, regular solid fixation, obsession with harmony and the fact to consider that music and astronomy as sister sciences are just some features of the Pythagorean influence protruding on the surface of the work of Johannes Kepler. However, the presence of Pythagoras in the work of this scientist and philosopher of the 17th century can be traced more deeply on the methodological aspects.

${ }^{1}$ I am grateful to the Fund of research of the Universidad del Rosario (DVG-146) for the support given to the development of this research. I am also grateful for the contributions of Juliana Gutiérrez.

Manuscrito - Rev. Int. Fil. Campinas, v. 39, n. 3, pp. 91-120, jul.-set. 2016. 
It is not easy to establish precise information in relation to Py66thagoras and his school. In literature, there are plenty of anecdotes and stories with questionable evidence. Moreover, we don't count with primary documents with an outline of the main ideas of the members of the school. The most important source to characterize the ideas of Pythagoras is, unquestionably, Aristotle. The knowledge that Kepler could have ascribed ideas from the Pythagoreans comes mainly from three sources. Kepler was familiar with the works of both ristotle and Plato. Kepler had read and greatly appreciated the work of Proclus, a philosopher who lived in fifth-century Alexandria and wrote, among other works, a famous commentary on the first book of Euclid's Elements of Geometry. This comment, which profoundly influenced Kepler, could be considered -in the strictest sense- as the first book of philosophy of mathematics. I intend to show that Kepler's methodology is inspired primarily on two principles of Pythagorean origin. As a hypothesis, I will propose a general outline that identifies four corresponding elements that are present in Keplerian methodology. I will show how these principles are present in Pythagorean cosmology. Finally, I will try to trace the presence of these principles in the two particular following cases of the Kepler research program.

\section{Pythagorean elements in the methodology of Kepler}

First point: sameness is made known by sameness. The Pythagoreans, it is believed, aspired to resemble God. They considered the human soul is similar to the soul of the living universe. Thanks to this similarity the soul can know the world. This principle combines a maxim shared by almost all the pre-Socratic thinkers.

Second point: Knowledge searches for harmony present in the world and this harmony arises from establishing a limit to the unlimited For the Greeks harmony implies the pairing between two dissimilar elements. The Pythagorean paradigm for harmony comes from music. The music that Pythagoras was familiar with was constructed from three basic intervals that serve as elements of every composition. These three intervals are the octave, fourth and fifth. Pythagoras associated these intervals with simple numeric relationships. For example, if the lengths of two strings of identical material are in a ratio of

Manuscrito - Rev. Int. Fil. Campinas, v. 39, n. 3, pp. 91 - 120, jul.-set. 2016. 
$1: 2$, the sounds that they produce after being made to vibrate have the relationship of an octave. If the lengths are in the ratio of $3: 2$, the difference of tone corresponds to a fifth, and if they are in the ratio $4: 3$ the interval corresponds to a fourth. Criteria or arguments that led to this discovery by Pytagoras are not known. The important thing is that underlying harmony in musical composition is governed by simple numerical relationships. So according to Pythagoras, a chaotic combination of sounds could not be expected to result in a pleasing melody. Harmony must therefore arise after limiting the infinite number of random possible sounds to certain peculiar combinations. The fact that these combinations exhibit simple numerical ratios suggests that musical harmony is twinned, or related, with some form of numerical harmony.

When Proclus spoke of the importance of harmony in philosophical inquiries, he used to rely on the teachings of Socrates in Phaedrus. Proclus refers to the profiles of three kinds of men that aim for the go to the highest ideals: the lover, the musician and the philosopher. The first one begins his journey attracted by the appearance of beauty; the musician is, at first, moved by the harmony that he listens to, but soon turns his gaze towards harmonies that he does not hear and that are proportionally gathered together with things that are related to harmony. The Philosopher, who cannot be aided by sight nor sound, must rely on, mathematics if he wants to explain the intangible nature of harmony: "when he [the philosopher] uses this [math] as a model, he can be led to the practice of dialectic and to the contemplation of being in general" (Proclus, trad. 1970, p. 18).

From this similarity between musical harmony and numbers, it is natural for the reader to infer some kind of affinity between numbers and the universe as a whole. Indeed, says Aristotle, " [the Pythagoreans] saw that the modifications and the ratios of the musical scales were expressible in numbers; -since, then, all other things seemed in the whole nature to be modelled on numbers, and numbers seemed to be the first things in the whole of nature, they supposed the elements of numbers to be the elements of all things, and the whole heaven to be a musical scale and a number" (Metaphysics, 985 b 31-986 a, 2). Thanks to Aristotle, the Pythagoreans became famous for trying to find in numbers in the beginning of all things. The problem for the interpreter, including Aristotle, is to define whether Pythagoreans are claiming the following: (1) either all things consist of 
numbers, i.e., physical bodies are made of numbers, and in that sense things themselves are numbers ${ }^{2}$; (2) physical bodies mimic (resemble) numbers ${ }^{3}$; or (3) the principles of things are also the principles of numbers. ${ }^{4}$

The general principle for conceiving the order or harmony in the world is reduced to, the imposition of a limit to the unlimited. The first imposition of a limit on the unlimited is given by the creation of the unit, the starting point of the numerical series. This is how Aristotle examined the subject, "the pythagoreans have said in the same way that there are two principles but added this much $[\ldots]$ that they thought that finitude and infinity were not attributes of certain other things [...] but that infinity itself and unity itself were the substance of the things of which they are predicted" (Metaphysics, 987 a, 14-19). Thus, numbers arise when, by imposing a limit to the unlimited, the unit is born and, by the iteration of the unit, we can build the numerical series. ${ }^{5}$

In geometry, the unit is known as the point. The transition towards higher forms should reach the composition of bodies. Let's see a possible interpretation of the sequence. Aristotle explains: "Some [Pythagoreans] think the limits of body, i.e. surface, line, point, and unit, are substances, and more so than body or the solid" (Metaphysics, 1028 b, 16-18).6 A kind of primitive (or primary) conflict is resolved when a limit is imposed on the unlimited. Thus we see the birth of unity. When unity is multiplied in an unlimited horizon, it gives rise to the line, "This is why in the higher region the point is completely without parts and yet, although its being is determined by the Limit, it secretly contains the potentiality of the Unlimited, by virtue of which it generates all intervals" (Proclus, trad. 1970, p. 72). Now let's consider the straight line as a limitless flow of points in

\footnotetext{
${ }^{2}$ Metaphysics, 987 b, 28-30

${ }^{3}$ Metaphysics, 987 b, 11

${ }^{4}$ Metaphysics, 985 b, 32

5 Proclus presents it like this: «among immaterial forms unity is more perfect tan plurality, the partless more perfect than what proceeds in any way from it, and what bounds more perfect tan what gets its limits from something other than itselfin (Proclus, 1970, p. 70).

${ }^{6}$ See also: «But let us recall the more Pythagorean doctrine that posits the point as analogous to the monad, the line to the dyad, the Surface to the triad, and the solid to the tetrad» (Proclus, 1970 , p. 80).
}

Manuscrito - Rev. Int. Fil. Campinas, v. 39, n. 3, pp. $91-120$, jul.-set. 2016. 
either of the two directions. If we impose a limit on the Unlimited we have to do it through points that limit the two extremes. Therefore, the segments with lengths limit the indefinite extension of the straight. If we let a straight line multiply in new directions, we contemplate the birth of planes. If we want to limit the unlimited expansion of the plane, we have to use straight lines. The straight lines enclose and, thereby, limit surfaces. Points cannot confine fragments of surfaces. If we allow a plane to multiply in new directions, the space thereby generated is three-dimensional. In addition, if we wish to limit that unlimited space, we we must let the surfaces do the work. The areas enclose the solid thus allowing a limit to be imposed on the unlimited. This is the support that Proclus gives, "every being simpler than what immediately follows it supplies a boundary and limit to its successor [...] So also in geometry the solid is bounded by the surface, the surface in turn by the line, and the line by the point, for the point is the limit of them all" (Proclus, trad. 1970, p. 93). Figure 1 shows evolution.

Thus, we have arrived at a creation plan for geometric objects that represents a progression from the standard of imposing a limit on the unlimited. This allows us to take the leap toward a continuous transition from three-dimensional geometric solids to physical objects. Plato, in fact, associates regular solids with physical elements (earth, water, air, fire). Yet, there are still doubts for ascribing this reasoning to Pythagoras. ${ }^{7}$ Proclus attributed to Pythagoras The discovery of the five regular solids: ${ }^{8}$ "Pythagoras transformed mathematical philosophy into a scheme of liberal education [...] he it was who discovered the doctrine of proportionals [irrational] and the structure of the cosmic figures [regular solids]" (Proclus, trad. 1970, p. 53).

In another passage the commentator notes: "The surface is both triad and dyad, being the receptacle of the primary figures as well as the first nature that takes on form, it resembles both the triad that primarily bounds all being and also in a way the dyad which divides this triadic nature"

\footnotetext{
7 Aristotle criticizes Plato's association of regular solid elements and refrains from ascribing this view to the Pythagoreans (De Caelo, III, caps. 7 and 8).

${ }^{8}$ Heath argues that although one can not rule, there is reason to believe that the Pythagoreans could not have a complete understanding of the peculiar nature of the five regular solids; cfr. T. Heath, 1981, I, pp. 158-162.
}

Manuscrito - Rev. Int. Fil. Campinas, v. 39, n. 3, pp. $91-120$, jul.-set. 2016. 
(Proclus, trad. 1970, p. 81). If we give credit to Proclus and impose the principle of harmony, we can think in the following terms. There are an infinite number of possibilities to enclose a solid with flat surfaces. We can, however, limit the number of possibilities if we restrict the solids that we wish to use in the construction, taking into consideration only those that can be enclosed with regular polygons: first, those that are identical in form; second, those that are assembled in congruent solid angles. Only five solids can be built in the above fashion (Euclid, 1956, XIII, prop. 18). It was Plato in Timaeus who popularized the association of the cube nature with earth, the icosahedron with water, the octahedron with air and the tetrahedron with fire. It's not entirely clear who was the one who started to associate the dodecahedron with the celestial element. Kepler did not hesitate to accept the Plato's association. This is seen in the beautiful drawing which accompanies the publication of The Harmony of the World, the cube is decorated with objects associated with the element of earth, the icosahedron with objects from water, the octahedron with objects from of air, the tetrahedron with those from of fire and the dodecahedron with the infinity sky (Figure 2). That illustration also features a starry dodecahedron (Ss), which, as we will see, was used by Kepler to explain some irregularities about the structure of the heavens.

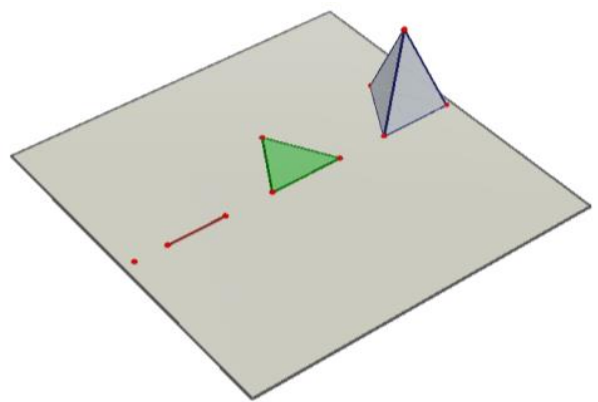

Figure 1. From the point to the solid

Manuscrito - Rev. Int. Fil. Campinas, v. 39, n. 3, pp. $91-120$, jul.-set. 2016. 


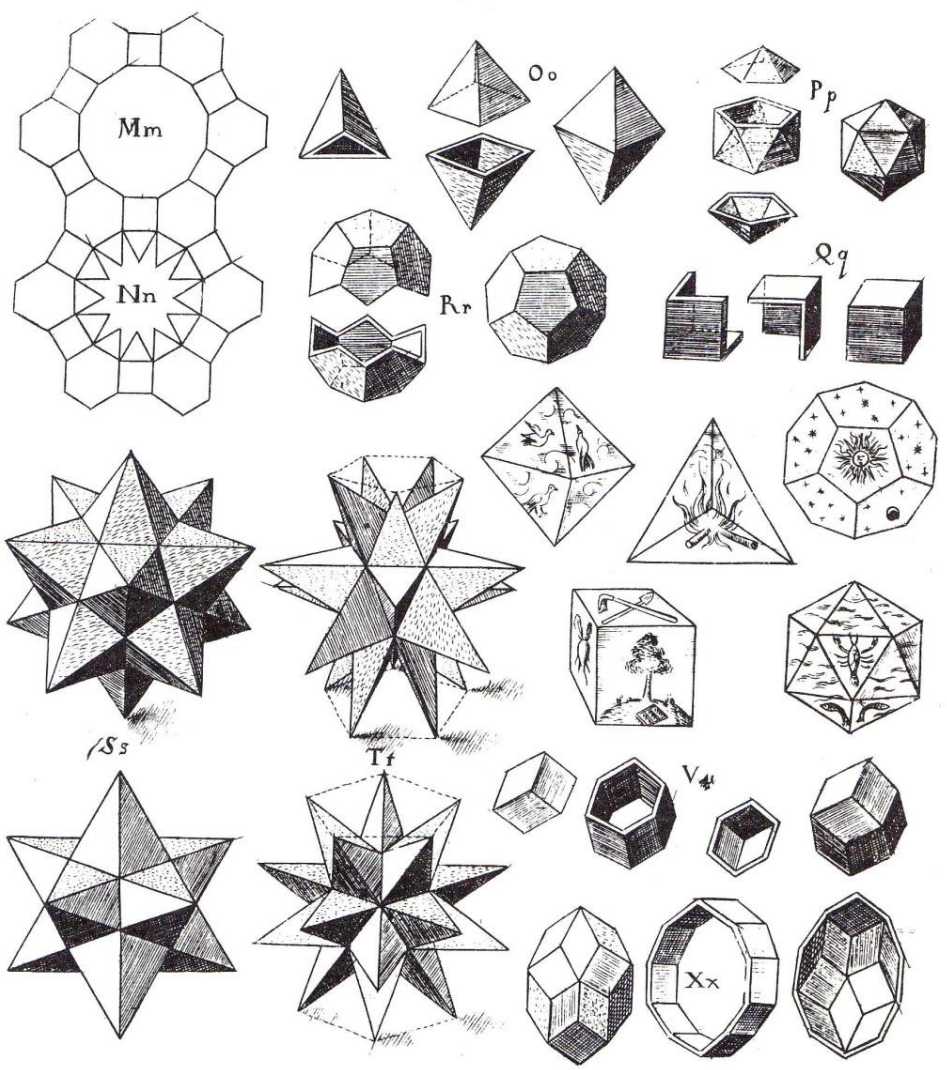

Figure 2. How the plane can be delimited. Kepler, The harmony of the world 9

I contend that Kepler's methodology was heavily influenced by of the spirit of Pythagoras. This spirit, as I suggested earlier, was mainly absorbed from the author's contact with the work of Proclus. Books I, III and IV of The Harmony of the $W$ orld begins with epigraphs taken from Proclus. Take, for

${ }^{9}$ J. Kepler, 1997, p. 111.

Manuscrito - Rev. Int. Fil. Campinas, v. 39, n. 3, pp. 91-120, jul.set. 2016. 
instance, the headings referred to books I and III. In the book one can read, "Mathematics also makes contributions of the very greatest value to physical science. It reveals the orderliness of the ratios according to which the universe is constructed and the proportions that binds things together in the cosmos [...] It exhibits the simple and primal causal elements as everywhere clinging fast to one another in simmetry and equality" (Proclus, trad. 1970, p. 19).

The epigraph to Book III reads as follows:

For theology, first of all, mathematics prepares our intellectual apprehension. Those truths about the gods that are difficult for imperfect minds to discover and understand, these the science of mathematics, with the help of likenesses, shows to be trustworthy, evident, and irrefutable. It proves that numbers reflect the properties of beings above being and in the objects studied by the understanding reveals the powers of the intellectual figures. Thus Plato teaches us many wonderful doctrines about the gods by means of mathematical forms, and the philosophy of Pythagoreans clothes its secret theological teaching in such draperies. (Proclus, trad. 1970, pp 18-19)

Assuming an epigraph by an author intends to rely on the authority of the other to provide a first approach to that of which it purports to address, there is no doubt that these epigraphs intend to highlight the presence of Pythagoras and Plato in the work offered to the reader. Through Mathematics we reveal the harmony which the universe. When finite minds attempt to fathom the unfathomable, they find themselves mired in the deepest labyrinths and obscurities. However, if humans decide to rely on mathematics toward finding an appropriate 'likeness,' they will see how the most difficult truths become naturally graspable: it makes one think that they were always lurking there. If we get swept away by this heuristic, we may come to recognize that numbers (mathematics) or intellectual figures (geometry) reflect — or embody, as a radical Pythagorean would say - the very essence of things. Addressing this point related to assessing the supposed geometric structure that underpins the world also relates to personal character development: the harmony of the universe deeply

Manuscrito - Rev. Int. Fil. Campinas, v. 39, n. 3, pp. 91 -120, jul.-set. 2016. 
determines the aspects that accompany the development of our own characters.

\section{The Keplerian Leitmotiv}

I will show that in addition to the results of his research, some aspects of the Keplerian methodology can be better understood if we try to assimilate them to the methodological principles already presented: (i) sameness is made known by sameness and (ii) the harmony arises when a limit is imposed to the unlimited.

In Chapter 4 of Paralipomena ${ }^{10}$, after Kepler criticized all the efforts made to date to find a law of refraction (especially John Pechan and Witelo) and after suggesting the possibility that a study of conics could shed light on the matter, the author brilliantly summarizes what we might call the leitmotiv ${ }^{11}$ of the Keplerian methodology. Consider the passage:

For geometrical terms ought to be at our service for analogy. I love analogies most of all: they are my most faithful teachers, aware of all the hidden secrets of nature. In geometry in particular they are to be taken up, since they restrict the infinity of cases between their respective extremes and the mean with however many absurd

\footnotetext{
${ }^{10}$ After the dealth of Tycho Brahe (1601) and after the conflict raised between the heirs of the astronomer and the emperor, Kepler had to reorientate his work plan as a researcher. In a letter in 1602 to his friend Herwart, he confesses that he has decided to concentrate, on the one hand, on a review of the optical part of astronomy and, on the other hand, on a careful study of the orbit of Mars. (cfr. J. R. Voelkel, 2001, p. 147). The first work led to the preparation of its Ad vitelionem paralipomena, quibus Astronomica pars optica (1604), hereafter abbreviated with the reference: Paralipomena. This work, written in a way of critic comments to the optics of Witelo, became, ultimately, the source of the fundamental revolution in the study of optics. The second work culminated in the publication of his Astronomia nova (1609) which would contain the strongest developments aimed at strengthening the Copernican revolution.

${ }^{11}$ I use the German Leitmotiv voice precisely because in music it refers to the recurrent theme in a composition.
}

Manuscrito - Rev. Int. Fil. Campinas, v. 39, n. 3, pp. 91-120, jul.-set. 2016. 
phrases, and place the whole essence of any subject vividly before the eyes. $(1604 / 2000$, p. 109)

When the investigator of nature, according to Kepler, is confronting a problem, he assumes that nature hides a key that does not emerge naturally on the surface. Since the Pythagorean also assumesd that the deep harmony of the world can only be unraveled in mathematical terms, Kepler recommends comparing an analogy to the problematic situation in order to expose the secret we want to reveal. The problem, usually has this abstract form: given that nature behaves in a regular manner (limited appearance) even though it could have behaved in many possible ways, there must be a reason in nature that determines the restriction. The researcher searches for the reason whereby endless logical possibilities are reduced to a smaller number of possibilities. The researcher seeks a geometric analogy: this involves identifying a mathematic resource that provides a system of finite control over the infinite; aside from the differences, the resource offers the same behavior on the surface as that exhibited by the particular aspect of nature that is the cause of the problem. I will now attempt to illustrate this methodological approach using specific cases.

We have seen that in the case of Pythagoras, the imperative is to impose a limit on the unlimited: this can provide an approach to rational construction progresses with respect to from the elements of the material world (earth, water, air, fire, ether). In his commentary on Greek mathematics, Proclus offers a recommendation akin to this methodological process. I unswervingly believe that Kepler found the deepest substance in this process. In Kepler, there is no better expression of an updated Pythagoreanism - one that exceeds the original Pythagorean mystical roots. We quote the commentator:

Mathematicals are the offsprings of the Limit and the Unlimited, but not of the primary principles alone, nor of the hidden intelligible causes, but also of secondary principles that proceed from them and, in cooperation with one another, suffice to generate the intermediate orders of things and the variety that they display. This is why in these orders of being there are ratios proceeding to infinity, but controlled by the principle of the Limit. For number, beginning with unity, is capable of indefinite increase, yet any number you choose is finite;

Manuscrito - Rev. Int. Fil. Campinas, v. 39, n. 3, pp. 91 -120, jul.-set. 2016. 
magnitudes likewise are divisible without end, yet the magnitudes distinguished from one another are all bounded, and the actual parts of a whole are limited. If there were no infinity, all magnitudes would be commensurable and there would be nothing inexpressible or irrational, ${ }^{12}[\ldots]$ nor could numbers exhibit the generative power of the monad, nor would they have in them all the ratios [...] that there are in things. And if the Limit were absent, there would be no commensurability or identity of ratios in mathematics, no similarity and equality of figures, nor anything else that belongs in the column of the better. ${ }^{13}$ There would not even be any sciences dealing with such matters, nor any fixed and precise concepts. Thus mathematics needs both these principles as do the other realms of being. As for the lowest realities, those that appear in matter and are moulded by nature, it is quite obvious at once that they partake of both principles, of the Unlimited as the ground that underlies their forms and of the Limit by virtue of their ratios, figures, and shapes. It is clear, then, that the principles primary in mathematics are those that preside over all things. (Proclus, trad. 1970, pp. 5-6)

Later Proclus adds "And certainly beauty and order are common to all branches of mathematics, as are the method of proceeding from things better known to things we seek to know and the reverse path from the latter to the former, the methods called analysis and synthesis" (Proclus, trad. 1970, p. 6-7).

We can venture to offer two interpretations. Under one interpretation, Proclus suggests the transit from the axioms (which are known) to theorems (what we want to know), i.e. the synthesis, and also suggests the breakdown of what is already known (or given) to underlying principle, i.e. the analysis. Under the other interpretation, Proclus anticipates the keplerian leitmotiv, namely: contrast an analogy to what we want to know, an analogy that displays in pristine shape what we already recognize as given in the first principles.

\footnotetext{
12 Refers to incommensurable magnitudes as $\sqrt{2}$.

${ }^{13}$ Proclus refers to the list of principles that Aristotle ascribes to the Pythagoreans and presented in a series of ten opposites: limit-unlimited, odd-even, unity, plurality, right-left, male-female, rest-motion, straight -curved, light-dark, good-bad, squarerectangle. (Cfr. Metaphysics, 986 a, 23-27).
}

Manuscrito - Rev. Int. Fil. Campinas, v. 39, n. 3, pp. $91-120$, jul.-set. 2016. 
Gerd Buchdahl, in an interesting article on exposing the methodological aspects of Kepler's work, suggests that the use of analogies (archetypes, the author says) function in the manner of regulative principles. ${ }^{14}$ Basically, I do not feel comfortable with this recommendation. I can think of only two ways of understanding law as a regulative principle. First, regulative principles are not laws that describe a series of phenomena: they are the basis for constructing such laws. This is evident, for example, with the principle of conservation of energy or principle of minimal action. In the former case, we find that something is actually preserved; we postulate the way we want to give a set of laws however. We want these laws to prescribe the conservation, which with progressive research, we will elucidate more precisely in a better form. In the case of minimal action, we search for laws that minimize something, which, as soon as research advances, we can later define more precisely.

Second, a law may prescribe the meaning of a concept that we wish to introduce. However, the law does not do so in an explicit way: the meaning of the concept is presented simultaneously with the law's creation. This occurs, for example, in Newton's first law. That law does not infer, deduce, or a priori impose the behavior of entities known as 'forces': it sets out how we use the term 'force' within the system it aims to build.

However, from my perspective, Kepler's use of regulative principles is unrelated to the two meanings that I have identified above. As we will see, Kepler's use does not prescribe the form of a law nor does it introduce new concepts to a system. I will attempt to demonstrate how the analogies mentioned function as instruments of control: I will put these instruments aside in complex cases (involving the presence of infinite possibilities) so as to highlight any hidden metaphysical causality. Finding an adequate analogy does not imply an inductive process (or following a clear pattern of deduction from metaphysical principles). Finding the appropriate analogy is a matter of heuristic research. A clue here is evident in the passage I quoted

14 Cfr. G. Buchdahl, 1972. Buchdahl, however, also ascribes the analogies also a function tied to justification. The second use may be closer to what I want to defend here. The author says: «Methodologically, they [the archetypes, or analogies] act as necessary rules, regulative maxims; whilst epistemologically, they function as principles of justification» (G. Buchdahl, 1972, p. 276).

Manuscrito - Rev. Int. Fil. Campinas, v. 39, n. 3, pp. 91-120, jul.-set. 2016. 
earlier: "In geometry in particular they [the similarities] are to be taken up, since they restrict the infinity of cases between their respective extremes and the mean with however many absurd phrases, and place the whole essence of any subject vividly before the eyes" (Kepler, 2000, p. 109).

I propose to expand the leitmotiv of the Keplerian methodology in the following stages:

(i) Formulation of the problem. Many of the problems of natural philosophy that Kepler confronts, perhaps the most important, usually have the following general form: given that the phenomena in a restricted field exhibit a regularity such that, even though we would expect infinite logical possibilities, only a small number of these possibilities are presented on a regular basis, we may well come to believe that there is a profound metaphysical reason that explains why these possibilities are restricted if, in principle, anything could be expected. We ask, then, what is the metaphysical cause that restricts the possibilities? Studies searching for efficient causes are not the ones that Kepler is worried about. Kepler was not overly concerned about research into the causes in this regard. I may enquire about the efficient cause of X: if I do so, it is because though I recognize that X is the case, I may also admit that X might not be the case. If $\mathrm{X}$ is not the case, that does not carry any contradiction with higher principles. When the questions that occupied Kepler expose a metaphysical causality, it is because they incorporate a metaphysical necesity. Such metaphysical necessity is closely linked to the assumption of order and harmony in the world: in the Pythagorean sense, that implies a limit being imposed on the unlimited. That metaphysical necessity is closely linked to the assumption of order and harmony in the world, what in the Pythagorean sense implies that a limit is imposed on the unlimited.

(ii) Search for a contrasting analogy. Given a problem, I must admit that the foundation of the harmony that I presume is hidden from me in some way. If I could contemplate such harmony firsthand -as Pythagoras might suppose God to do- the problem would not be such an enigma. If I recognize the inherent difficulty here and feel inclined to assume this harmony, I believe that appearances would conceal the essence of regularity. In that sense, I must try to make the symmetry become apparent. Now if I assume that the order (harmony) arises because the limit is imposed to the unlimited, I can

Manuscrito - Rev. Int. Fil. Campinas, v. 39, n. 3, pp. 91 -120, jul.-set. 2016. 
imagine that mathematics (geometry in particular) provide a tool that allows me to make manifest the harmony underlying the problematic situation. Thus, I will proceed to find a mathematical analogy that looks for the following: (1) mathematical rules that provide finite resource control over the context of infinite possibilities; and (2) the resource fits the problem situation. The second point is important since similarity is known by similarity. In this regard, a situation that is unknown to me may become understandable if $\mathrm{I}$ am able to compare it with a situation that is more familiar. Analogy is an instrument of finitary control: it allows a person to grasp relationships that determine the imposition of a limit on the unlimited. If a question concerns metaphysical causality, this represents a problem that touches on infinite potentiality. Metaphysics offers order over absolute chaos: it limits the available possibilities.

(iii) Deployment of obstructions. The creative power of the researcher lies in finding the right analogy. To recognize such an analogy and follow it is the central heuristic of the researcher. In that sense, there is no virtuous researcher who is not, at the same time, a stubborn researcher. When it comes to stubbornness, it is hard to find a specimen that exceeds Kepler. Analogies are never coupled with absolute ease. In fact, analogies refer to quite simplified ideal situations. We have no grounds to expect that natural regularities that cause perplexity gather all the elements that we can find in an analogy. Hence, it is no wonder that the unfolding of the criteria of finite control applied to the mathematical tool, i. e., the conditions imposed by analogy, produce results that differ from the natural circumstances in which information of the world is collected. Faced with difficulty, the researcher who gives up without trying again is a researcher who is not going to go very far. This does not suggest that one who perseveres succeeds; however, it does suggest that one who does not persevere will not succeed. Once the researcher realizes the obstructions, he never abandons the potential he sees in the analogy, he should make adjustments to the analogy in order to guarantee a better fit, or he should find the material circumstances that explain why a better fit isn't possible. Either case requires work on the analogy to make it more robust.

(iv) Harvest of results. A persistent piece of work in the direction shown may result in three types of outcome. (1) A finally successful match: in this case the research project reaches the goal with the expected 
results. We have, in this case, the criteria of finite control over the infinite, criteria that can be presented as the metaphysical basis of the observed regularity (end of the research). (2) A coupling that although frustrating produces interesting results: the analogy does not successfully capture rules of finite control that reproduce the regularities; however, in the process of sophisticating the couplings, the analogy attains new regularities which we possibly could not have obtained without the rigor adopted in our search. These results can be introduced to the research tradition ignoring the convoluted paths typical in the logic of discovery. (3) A coupling suggests that the outcome is unattainable: the researcher decides to give up what appeared to be a promising hope for the analogy. It may be that the researcher discovers why the proposed analogy cannot be chosen as the expected coupling: the research project might result in profit; or it may be that without being able to explain why, the investigator decides to explore a totally different analogy and restart the project in a new direction.

Consequently, a given complex case (which includes choosing a finite number of choices among an infinite number of possibilities), what is required is the search for a case that can be offered as an analogy, one that provides finite control rules over a reality whose variables are controlled absolutely. We would expect the analogous case to offer desired restrictions with respect to the complex case. These analogies create universes with control rules that are in our power. The analogy can then access a world where there are control variables. The Keplerian Leitmotiv can be summarized in the words of Hedwig Zaiser, "Harmony is present when a multitude of phenomena is governed by a mathematical law unit that expresses a cosmic idea" (1932, p. 47). Charles Sanders Peirce, meanwhile, presents the method of Kepler in this way: "His admirable method of thinking consisted in forming in his mind a diagrammatic or outline representation of the entangled state of things before him omitting all that was accidental, retaining all that was essential, observing suggestive relations between the parts of the diagram, performing divers experiments upon it, or upon the natural objects, and noting the results" (Ch. S. Peirce, 1985, p. 294).

Manuscrito - Rev. Int. Fil. Campinas, v. 39, n. 3, pp. 91-120, jul.-set. 2016. 


\section{Case Studies}

We are going to focus on two specific examples that allow us to illustrate the proposed methodology.

First case: the planets of the solar system.

(i) Formulation of the problem. The three central questions that bring together all the attention to the Mysterium Cosmographicum are: (1) why are there six planets? Kepler was unable to investigate other solar systems, which might have suggested that six is a normal number of planets; however, the astronomer believes that the number of planets in the solar system is not random. The number could very well be 4, 8, 9, or 273, and so on; there must be some limit to obtain precisely that number. (2) Why are the planets distributed as they are around the sun? Why are they located in that specific place if they could be scattered around space? ${ }^{15}$ (c) Why do the planets move more slowly depending on how far they are from the sun? The questions, then, point to the number, distance and movement of the planets (Numerus, Quantitas et Motus Orbium).16

(ii) Search a contrasting analogy. Once in Graz, when Kepler was talking to his students about the conjunctions of Jupiter and Saturn, he noticed features in the resultant plot: in a circle that included the positions of the zodiac, the segments of the line that linked the consecutive positions of these conjunctions in the sky produced a complex figure. It was a starry polygon with 40 corners and skips of 14 positions. The interesting thing about the drawing (Figure 3) is that the proportion between the diameter of the outer circle and the diameter of the circle drawn in the central part of the figure appeared to be, at first glance, the same proportion of that between the circle of Saturn and the circle of Jupiter. ${ }^{17}$ Regardless of

\footnotetext{
${ }^{15}$ These two questions today lack the importance that Kepler tried to give. Kepler sought a kind of necessary reason. Today we face the questions looking for completely contingent causes. So then, Kepler's example illustrates an interesting case of a program that offers surprising results obtained by trying to answer a question that no longer worries us.

${ }^{16}$ J. Kepler, 1596/1999, p. 66.

17 The ratio of the radius of the larger circle and the lowest is 1.91 , the ratio of the radius of the orbit of Saturn and Jupiter is 1.82 .
}

Manuscrito - Rev. Int. Fil. Campinas, v. 39, n. 3, pp. 91-120, jul.-set. 2016. 
whether or not his observation was correct, Kepler noticed in this way the general structure of a research project: if the planets could be distributed in a spectrum of infinite possibilities, a rule of finite geometric control would restrict the possibilities to what actually exists. Thus, he recognized the possibility of introducing (geometric) mathematical objects that allow us to address questions that seek to bring to light what is unknown. ${ }^{18}$ Kepler then realized it that he should not restrict his investigation to plane figures, and focused on three-dimensional solids. Many trials led him to state the central thesis of the Mysterium, namely, since you can only build five regular solids inscribed in a sphere, then this determine that there are only six planets in the solar system. The larger sphere must contain the orbit of Saturn, Inside that sphere you can draw a cube in which, likewise, you can draw a sphere that, determines the orbit of Jupiter. In Jupiter's sphere you can draw a tetrahedron which, in turn, circumscribes a sphere that corresponds to the orbit of Mars. In Mars's sphere one can draw a dodecahedron which circumscribes the sphere of the Earth. The sphere of the Earth circumscribes an Icosahedron which embraces the Venus's sphere. The Venus's sphere circumscribes an Octahedron, which finally embraces the sphere containing Mercury. Kepler's arguments for choosing this the sequence especially allude to free speculation, some of them associated with astrological expectations and others associated with musical harmonies.

${ }^{18}$ Kepler also thought that Jupiter's orbit would fit polygons similar but with a different number of sides or skips. These trials did not lead to anything interesting.

Manuscrito - Rev. Int. Fil. Campinas, v. 39, n. 3, pp. 91-120, jul.-set. 2016. 


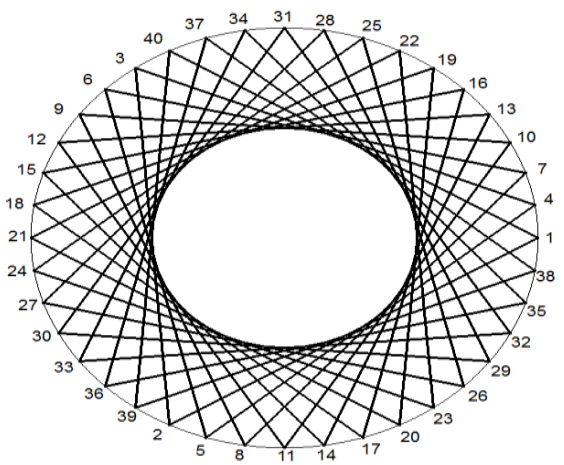

Figure 3. Diagram that reproduces the argument of the Mysterium Cosmographicum

(iii)Deployment of obstructions. The first data Kepler had on hand strayed too far from expected calculations. When Kepler had access to the information that Tycho Brahe (1546-1601) had collected and after noticing the hypothesis of elliptical orbits of the planets, Kepler felt obliged to restructure his initial hypothesis. Kepler took into account the eccentricities of the orbits of the planets, and it gave him a wider interval of tolerance: he evaluated the possibility of establishing the relationships among the planets using perihelion distances, aphelion distances, or combinations thereof. The Harmony of the World is as follow (Table 1):

\begin{tabular}{cc} 
Planet & Distance measured from the sun \\
\hline \hline Saturn & 9.510 \\
Jupiter & 5.2 \\
Mas & 1.524 \\
Earth & 1 \\
Venus & 0.724 \\
Mercury & 0.388
\end{tabular}

Table 1. Position of the planets ${ }^{19}$

the distance is taken as the astronomical unit

${ }^{19}$ Cfr. J. Kepler, 1997, p. 422.

Manuscrito - Rev. Int. Fil. Campinas, v. 39, n. 3, pp. 91 - 120, jul.-set. 2016. 
The following Table 2 allows us to compare the relationship of the inscribed orbits stablished by Kepler with the derived from the empirical data available for the astronomer when he wrote The Harmony of the World.$^{20}$

\begin{tabular}{cccc}
$\begin{array}{c}\text { Coupled } \\
\text { Planets }\end{array}$ & $\begin{array}{c}\text { Regular solid } \\
\text { interposed }\end{array}$ & $\begin{array}{c}\text { Expected } \\
\text { relationship } \\
\text { between the } \\
\text { orbits }\end{array}$ & $\begin{array}{c}\text { Observed } \\
\text { relationship } \\
\text { between the orbits }\end{array}$ \\
\hline \hline Saturn-Jupiter & Cube & 0.577 & 0.5468 \\
Jupiter-Mars & Tetrahedron & 0.333 & 0.2931 \\
Mars-Earth & Dodecahedron & 0.7946 & 0.6562 \\
Earth-Venus & Icosahedron & 0.7946 & 0.724 \\
Venus-Mercury & Octahedron & 0.577 & 0.5359
\end{tabular}

Table 2. Kepler's hypothesis

The distance between the expected and observed data would force a contemporary astronomer to abandon the defense of the hypothesis in question. However, Kepler was a stubborn astronomer. The orbit of the Earth does not even touch the sides of the proposed dodecahedron; neither does Venus with the corresponding icosahedron. This led him to propose an ad hoc modification. He suggested to place a star in-between Mars and Venus; such star would be constructed from with five equilateral triangles laid down outward and raised from the edges of each of the pentagons that constitute a dodecahedron. ${ }^{21}$ The apex of 60 equilateral triangles converge in groups of five: through 12 vertices that touched the orbit of Mars, the dodecahedron would serve as the basic construction for circumscribing a

\footnotetext{
${ }^{20} \mathrm{Cfr}$. J. Kepler, Epitome of Copernican Astronomy, p. 29.

${ }^{21}$ Kepler calls it Hedgebog (Hedhegog) cfr. J. Kepler, 1619/1997, p. 407. The star that Kepler has in mind appears as one of the geometric objects (Ss) in the sheet reproduced in Figure 2.
}

Manuscrito - Rev. Int. Fil. Campinas, v. 39, n. 3, pp. $91-120$, jul.-set. 2016. 
sphere that enclosed Venus. ${ }^{22}$ Even when the connection is closer, the whole system loses a good deal of the elegance it offered at the preliminary stageWe will now read a quote from the author's thoughts, which could be presented as a sample of careful reasoning behind a promising conjecture:

From that fact [the lack of a precise fit between the observed and expected data] it is evident that the actual proportions of the planetary distances from the Sun have not been taken from the regular figures alone; for the Creator, the actual fount of geometry, who, as Plato wrote, practices eternal geometry, does not stray from his own archetype. And that could certainly be inferred from the very fact that all the planets change their intervals over definite periods of time, in such a way that each one of them has two distinctive distance from the Sun, ${ }^{23}$ its greatest and its least; and comparison of distances from the Sun between pairs of planets is possible in four ways, either of the greatest distances, or of the least, or of the distances on opposite sides when they are furthest from each other, or when they are closest. Thus, the comparisons between pair and pair of neighboring planets are twenty in number, whereas on the other hand there are only five solid figures. However, it is fitting that the Creator, if He paid attention to the proportions of the orbits in general, also paid attention to the proportion between the varying distances of the individual orbits in particular, and that that attention should be the same in each case, and that one should be linked with another. On careful consideration, we shall plainly reach the following conclusion, that for establishing both the diameters and the eccentricities of the orbits in conjunction, more basic principles are needed in addition to the five regular solids. (1619/1997, p. 407).

Why did the astronomer stubbornly insist on a speculation that did not easily fit with the vast information when very fine details were taken into account? Perhaps the answer has to do with the Pythagorean spirit and character. Kepler was convinced that his answer had to reflect an intrinsic aspect of the profound harmony with which God had created the world. In the Mysterium, the author tested some arguments that established relations

${ }^{22}$ Cf. J. Kepler, 1997, p. 407.

${ }^{23}$ Kepler had already incorporated the elliptical orbits.

Manuscrito - Rev. Int. Fil. Campinas, v. 39, n. 3, pp. 91-120, jul.-set. 2016. 
among planets and the lengths of strings that determine harmonious combinations. ${ }^{24}$ In The Harmony of the World, Kepler again tries to find the relationships between the planet's orbits and the fundamental harmonic relationships. ${ }^{25}$ There is no doubt that Kepler is making an explicit suggestion that is found directly in the work of Copernicus. Indeed, this is what the Polish astronomer suggests: "Therefore, in this ordering we find that the world has a wonderful commensurability and that there is a sure bond of harmony for the movement and magnitude of the orbital circles such as cannot be found in any other way" (N. Copernicus, 1543/1955, p. 528).

Harvest of results. Kepler's questions led him to deal mainly with the metaphysical cause that would explain why the planets revolve around the sun at the speed they do. In the Astronomia nova Kepler initially tried to stay true to the Platonic axiom which assumes that the movement of the stars should be conceived as circular and uniform motions. After many failed attempts, Kepler was encouraged to replace circles by elliptical paths and uniform motions by a law establishing uniformity of the areas covered by the segment joining the Sun to the planet in question. Later, when Kepler worked in his Harmony of the world, without sacrificing the dominant presence of the embedded Pythagoreans solids, he arrived at the law which states says that the square of the period of the planets is proportional to the cube of the distance of the planet to the Sun. ${ }^{26}$ These three results were incorporated into the astronomical tradition, under the name of Kepler's laws, although this tradition chose to ignore completely the spirit of the research that led to them. Kepler sought deep harmony, he believed that it had to be reflected in an analogy that had to offer rules of finite control over the infinite, he looked for the best modifications to reconcile the principles of harmony and empirical data. In that search, he reached three results that the tradition incorporated, forgetting everything that led to them.

\footnotetext{
${ }^{24}$ This happens in chapter XII

${ }^{25}$ Cfr. 1997, Book V, chapters 3-9.

26 This result was obtained by imposing restrictions on the infinite possibilities, guided by the restrictions to be imposed to conceive a musical composition. See the interesting hypothesis suggested by Eric Werner (1967).
}

Manuscrito - Rev. Int. Fil. Campinas, v. 39, n. 3, pp. $91-120$, jul.-set. 2016. 


\section{Second case: cause of planetary movement}

(i) Formulation of the problem. Kepler was committed to a full defense of Copernicanism. i.e., a defense of the mathematical apparatus and physical hypotheses it assumed. So, if we are now convinced of the truth that the planets revolve around the sun, we have to ask why they move around the sun, if they could be turning around another center like Earth?

(ii) Searching for a contrasting analogy. If the planets revolve around the Sun, it is more natural to think that such a body is the root cause of this movement. Having said that, the Sun is also a source of light and hence, this is a source of life; therefore, so it is conceivable that the mechanism by which the sun radiates light is similar to the mechanism by which the sun radiates its driving force. Kepler now looks towards the radiant multiplication of species presupposed by the Neoplatonists and collected by English thinkers (Robert Grosseteste and Roger Bacon). Radiant multiplication is an interesting reference to the trinity: the point is the center of radiation, lines from there unfold and illustrate the process of multiplication and the expanding sphere presents the results of creation: Father, Son and Holy Spirit (point, line and spherical surface). In the first chapter of the Paralipomena, a chapter on the nature of light, Kepler expresses it as follows:

It was fitting that the nature of all things imitate God the founder [...] For in forming it [the Universe], the most wise founder played out the image of his reverend trinity. Hence the point of the center is in a way the origin of the spherical solid, the surface the image of the inmost point, and the road to discovering it. The surface is understood as coming to be through an infinite outward movement of the point out of its own self, until it arrives at a certain equality of all outward movements $[\ldots]$ And since these are clearly three -the center, the surface, and the interval- they are nonetheless one, inasmuch as none of them, even in thought, can be absent without destroying the whole. $(1604 / 2000$, p. 19)

The Sun is thus the paradigm of imitation of the creator. In it, the trinity is reflected: firstly, a focus, a source, a simple origin (geometrically a point), secondly, an outcome (geometrically a surface that has regularly extended or otherwise, would have a primitive cause of heterogeneity), thirdly, a

Manuscrito - Rev. Int. Fil. Campinas, v. 39, n. 3, pp. 91 -120, jul.-set. 2016. 
mediation that enables the item (unit) to be multiplied by endless manner (in all directions) until uniformity achieved. Proclus already discovered this idea: "For the circle, which is the principle of all curvilinear figures, carries a hidden trinity in its center, diameter, and circumference" (Proclus, trad. 1970, p. 93). In the Mysterium Cosmograpicum, Kepler had already imposed the analogy with a force that seemed definitive: "That I dared so much [to deal with the questions by the number of planets, distribution and velocity] was due to the splendid harmony of those things which are at rest, the Sun, the fixed stars and the intermediate space, with God the Father, and the Son, and Holy Spirit. This resemblance I shall pursue at greater length in my Cosmographia" (1999, p. 63). ${ }^{27}$

It is in the nature of light to be multiplied in all directions. Light, however, lacks matter, weight or resistance (Paralipomena, p. 8; I, prop. 3). Since light has no material nature, we cannot assign any threedimensionality. The so-called "ray of light" is not really a component of light. For Kepler, rays are the denomination of the multiplication paths from a center to the periphery. The source (lux, making reference to the meanings of the classic medieval language) resides in the center and the product (lumen) is displayed on the spherical surface. Light, then, corresponds to a two-dimensional nature.

One may conceive the emanation of an infinite number of lines from a particular point; the lines are distributed evenly across the surface, and though the original strength is retained, the density of the lines abates with their extension over the surface. This fact offers a rule, which determines the rate by which power decreases when moving the planets at increasing distance. This argument would have been able to bring Kepler closer to a law which would have anticipated a decrease in the strength with the square of in the distance. Kepler says in Paralipomena: "The ratio that holds between spherical surfaces, a larger to a smaller, in which the source of light is as a center, is the same as the ratio of strength or density of the rays of light in

${ }^{27}$ Also see 1596/1999 p. 93. In the Epitome Kepler presents the analogy again with Trinity and suggests that the Sun is conceived in the middle as the Father, the fixed stars on the surface, as the Son and the planetary system in the intermediate region as the Holy Spirit. The Sun is also conceived like an eye of the world, J. Kepler, 1618/1995, p. 14.

Manuscrito - Rev. Int. Fil. Campinas, v. 39, n. 3, pp. 91-120, jul.-set. 2016. 
the smaller to that in the more spacious spherical surface: that is, inversely" $(1604 / 2000$, p 22; I, prop 9). Thus, if the causal power density associated with light rays $(\delta)$ is inversely proportional to the surface $\frac{\delta_{2}}{\delta_{1}}=\frac{\operatorname{Sup}_{1}}{\operatorname{Sup}_{2}}$, the only thing Kepler needed was to concentrate on the fact that the surface area of a sphere is directly proportional to the square of the radius to be able to conclude that $\frac{\delta_{2}}{\delta_{1}}=\frac{r_{1}^{2}}{r_{2}^{2}} .28$ However, this hint turned out favouring an inverse relationship with the first power of distance. The resemblance to the creative power of God determined the intangible nature of light. Light therefore has no subject, weight or resistance. Its movement is developed instantaneously. The strength is in the center; on the surface you find is its manifestation.

(iii)Deployment of obstructions. If light, being immaterial, moves instantly, how come the denser material mediums seem to obstruct its movement? Since there is only interaction among similarities, solid objects (threedimensional) offer no resistance or modify light (two-dimensional, superficial). Hence, changes in the directions of propagation should be conceived as phenomena of surfaces: a surface modifies other surface. Therefore, if a body is heavier than another of the same dimensions, the first surface will be equally as heavy, and in that sense, it has the greater disposition to alter the direction of multiplication of light (1604/2000, p. 11; I, props. 13, 14). After alteration, mediation continues to run unchanged in a straight line until another area is encountered that limits two bodies of different nature.

Eager to find analogies in a simple manner that would allow us to glimpse the central aspects of complex phenomena, Kepler suggests that the power emanating from the sun is like that from a magnet. Thus, the Sun can be regarded as a great magnet and the planets as magnetized objects rotating around it. However, the language of the species presupposes that the source

\footnotetext{
${ }^{28}$ It is interesting to note here that Kepler sought to correct linear and inverse relationships defended in the Mysterium (1596/1999, p. 193-194) and to which he returns to in the Astronomia nova.
}

Manuscrito - Rev. Int. Fil. Campinas, v. 39, n. 3, pp. 91 -120, jul.-set. 2016. 
radiates simulacrums of itself. Therefore, if the planets, which receive species from the sun, show the action of the Sun with circular motions, we must admit that the Sun turns around its own axis. So if I assume that the sun rotates on its own axis and radiates species from the center (which operate as simulacra of the causal agency of the sun), we can imagine some sort of wind or whirlwind originating from the sun-a wind that causes the rotational movement of the planets. (Astronomia nova, cap. 34). For that reason, Kepler expected a Sun rotating around its axis long before Galileo offered empirical evidence of the same hypothesis derived from the contemplation of sunspots. There is, however, a big difference between the two results which seem equivalent. Galileo arrived at his result got his without any theoretical expectation; he did it after analysing the stains present in the images of the Sun collected on a screen. Kepler got his result as a metaphysical demand. Even when treated as a metaphysical demand, it got him from the causes (propter quid) to the effects (quia). This is not saying that Kepler first developed arguments for the sun rotating on its axis and then recognized that the rotation is transferred (by emanation of species) to the planets; rather, given that the planets revolve around the sun, the rotation must have derived from the sun, and we are obliged to admit that the sun rotates on its axis. The train of Kepler's reasoning leads me to believe that he concluded that the sun completes a revolution in 3 days. ${ }^{29}$

The power emanating from the sun is the same for all the planets, and the density differs only according to the distance of each planet to the sun;

${ }^{29}$ Kepler's argument, in brief, is as follows: (1) it is a fact that the radii of the orbits of Mercury and of a point on the sun's equator are the same (or similar) to the orbit of the moon and a point on the Earth's equator (according to current data, the first is close to 83.2, the second is 60.28). (2) The ratio between the ratio of the radii of the orbit of the moon and a point on the Earth's equator and the ratio of the translational period of the moon (close to 28 days) and the period of rotation of the Earth (1 day) is close to 2 (according to current data, it is close to 2.2). (3) If we assume that the above ratio is similar to the case of the Sun-Mercury couple, since the translation of the moon around the Earth depends on a similar power emanating from the Earth and affects the moon, causing it to simulate the rotation of the Earth, we can infer that the rotation period of the sun is close to 3 days (current data suggests that this is a value between 25 and 36 days). Cf. Astronomia Nova, chap. 34, p. 223.

Manuscrito - Rev. Int. Fil. Campinas, v. 39, n. 3, pp. 91-120, jul.-set. 2016. 
however, Kepler also recognized that the level of responsiveness of this power varies from planet to planet. According to Kepler, Saturn is less receptive to the power of the sun than Jupiter. These differences are important in providing an explanation for the fact that the translational periods of the planets do not decrease at the expected pace according to the reduction in power due to a planet's distance from the sun. Kepler proposed a sort of inertia of planets set to Aristotelian expectations, an inertia that determines the particular tendency of each planet to favour the resting state. So, a planet is always subjected to a double tension: first, the power emanating from the sun that seeks to set the planet in motion; second, the particular tendency of each planet to remain at rest. The first overcomes the second, but the resistance of the second offers the first explanation as to why the movement period is not consistent with the simple expectation that was determined by the sole intervention of the Sun. ${ }^{30}$

Perhaps the most powerful obstruction is this: why is the movement of the planets elliptical rather than circular? After several unsuccessful attempts, Kepler had to conclude in chapter 45 of Astronomia Nova that the matter was utterly obscure. In chapter 57 of the same book, he makes another desperate attempt to find a solution supported by another analogy: imagine asking a small boat sailing in a circle and introduce a rower who occasionally intervenes with his oar in the water. Kepler searches a rhythmic intervention from the rower that could force the boat to abandon its circular course. The chapter, however, does not produce any conclusive results.

(iv) Harvest results. Kepler's work paved the way for a complete physical interpretation of the solar system. The movement of the planets ceased to be conceived as a natural movement for which we had no reason to wonder about a cause different from its own nature Planets describe movements urged by the action that comes from the sun. We do not need to have complete sympathy for the keplerian analogy; we can always save the appearances based on the hypothesis that assumes that there is such an action.

${ }^{30}$ Cfr. Astronomia nova, cap. 34, p. 223.

Manuscrito - Rev. Int. Fil. Campinas, v. 39, n. 3, pp. 91 - 120, jul.-set. 2016. 


\section{Conclusions}

Kepler's works, in particular the Astronomia nova and Paralipomena, are a treasure for anyone who is interested in studying the methodology of creative genius, since the author makes no effort to hide or minimize the logic of discovery. The author presents his working hypothesis, he contrasts them with rival hypothesis, he exposes them to serious question, he offers the competing hypotheses all scenarios to answer the same objections and ultimately he makes the decisions that are best according to his exhaustive evaluation. I have tried to show that investigations that lead to deeper questions, i.e. questions that ask for a kind of necessity in the world, consist mainly in finding a metaphysical cause explaining why infinite logical possibilities are restricted, in fact, to a finite number of possibilities. I also suggested that, inspired by an orientation akin to the Pythagorean method, acquired through the work of Proclus, Kepler pursued a heuristic that consisted in finding a geometric analogy that could be opposed to the problematic situation. This analogy offers a rule of finite control over an infinite set of possibilities. Now if control rules limit the possibilities of the geometric space to the same opportunities as seen in the context of the problem, we must believe that we have reached some sort of privileged contemplation on the metaphysical causality that explains the harmony we observe in the physical world.

We identified the aforementioned heuristic in two of the most important investigations in Kepler's research agenda. First, to explain why the planets are located where they are; second, to stablish the reason why planets move the way they do. These two investigations led to establish the laws of the planetary system. These laws were incorporated as one of the most outstanding achievements of the tradition that founded the modern science in founding. Unfortunately, at the same time the aforementioned tradition completely ignored the heuristics that its creator brought into play. In the task of giving good grounds for the research program initiated by Copernicus, Kepler became fully aware of the need to address optics in cautious way; this with the purpose of adjusting the empirical information by being aware of the effects of of the refraction of light passing either through the celestial ether to the or through the air to the crystalline spheres that compose our visual. This exercise, as well Kepler understood it,

Manuscrito - Rev. Int. Fil. Campinas, v. 39, n. 3, pp. 91-120, jul.-set. 2016. 
demanded to have a precise law of refraction. Kepler devoted considerable time to developing this law. ${ }^{31}$ Though Kepler was unable to reach a satisfactory conclusion, the heuristic he brought into play could also be considered in terms of the background I have referred to as the Keplerian leitmotiv. To demonstrate this would, however, demand more space than is available in the present paper.

Other creative geniuses have used analogies. To mention just a few, several of Galileo's thought experiments could be considered in terms of analogies. Descartes also became involved with a well-known set of analogies when attempting to unravel the nature of light. The use of these analogies, however, differs greatly from that intended by Kepler. None of the analogies employed an instrument of finitary control over an infinite set of possibilities. Descartes used analogies as a mechanism to stir the imagination, while Galileo used them as a rhetorical device

Not all scientific exploration work can be examined using the same research model. In fact, I am inclined to believe that this model occurs only in projects that require exposing a metaphysical causality. In Paralipomena, Kepler faced and solved an old problem attributed to Aristotle without the use of the Pythagorean heuristics I have advocated here: namely, explaining how images are formed from objects when they are viewed through small holes (dark chambers). This issue was essential for two reasons: (1) Kepler obtained a significant amount of empirical astronomical information, especially during eclipses, using a dark chamber; and (2) it was difficult to interpret what was happening within the eye as a result of the dark chamber. Kepler solved that problem without deploying any of the heuristics mentioned in this paper. Kepler tackled the problem directly without using any instrument of finitary control as he tried to suggest in other cases.

\section{References}

ARISTOTLE. "Metaphysics". Transl. by McKeon, New York: Random House, pp. 689-934, trad. 1941.

${ }^{31}$ This work appears substantially in chapter 4 of Paralipomena.

Manuscrito - Rev. Int. Fil. Campinas, v. 39, n. 3, pp. 91-120, jul.-set. 2016. 
“De Caelo". Transl. by McKeon, New York: Random House, pp. 398-469, trad. 1941.

BUCHDAL, G. "Methodological Aspects of Kepler's Theory of Refraction". Studies in History and Philosophy of Sciences, no. 3, pp. 265-298, 1972.

Carolyne, E. (editor). "Historical Perspectives on Peirce's Logic of Science". A History of Science. Berlin: Mouton Publishers, 1985.

COPERNICUS, N. "De Revolutionibus orbium coelestium". Norimbergae: Johann Ptereius, 1543. Transl. by Charles Glenn Wallis, Chicago: Encyclopaedia Britannica, Inc (Britannica Great Books, vol. 16), 1543/1955.

EUCLID. "The thirteen books of the Elements". Transl. by Thomas Heath, New York: Dover Publications, INC, trad. 1956.

HeAth, Thomas SIR. “A history of Greek Mathematics". New York: Dover Publications, Inc. Vols. 1, 2, 1981.

KePler, J. Astronomia nova. Heidelberg, 1609. Transl. By Jean Peyroux, Paris: Librairie A. Blanchard, 1609/1979.

- Mysterium Cosmographicum. Württtemberg, 1596. Trans. By A. M. Duncan, Norwalk : Abaris Books, 1596/1999.

Epitome astronomiae copernicanae. 1618-1621. Transl. by Charles Glenn Wallis, Amherst: Prometheus Books, 1618/1995.

Harmonices Mundi. Linz: Johannes Plank, 1619. Transl. by E. J. Aiton, A. M. Duncan \& J. V. Field, 1619/1997.

Ad Vitellionem Paralipomena, Quibus Atronomiae Pars Optic.

Francfurt: Apud Claudium Marnium \& Haeredes Ioannis Aubrii, 1604. Transl. by William Donahue, Santa Fe: Green Lion Press, 1604/2000.

"Dioptrice". Transl. by Rolf Riekher, Frankfurt: Verlag Harri Deutch, pp. 441-526, 1611/2008.

LA RuE, J. (editor). “Aspects of Medieval and Renaissance Music”. London: Oxford University Press, 1967.

Manuscrito - Rev. Int. Fil. Campinas, v. 39, n. 3, pp. 91-120, jul.-set. 2016. 
PeIRCE, C. S. “Johann Kepler". In E, Carolyn (editor) (1985), Part. I, pp. 290-295.

PROCLUS. A "Commentary on the First Book of Euclid's Elements". Leipzig: Gottfried Friedlein, 1873. Transl. by Glenn R. Morrow, Princeton: Princeton University Press trad. 1970.

Voelkel, J. R. "The Composition of Kepler's Astronomia Nova". Pinceton: Princeton University Press, 2001

Werner, E. (1967). “The last Pythagorean musician: Johannes Kepler”, in J. La Rue, (editor), pp. 867-888, 1967.

ZAISER, H. “Kepler als Philosoph”. Stuttgart: E. Suhrkamp, 1932.

Manuscrito - Rev. Int. Fil. Campinas, v. 39, n. 3, pp. 91 -120, jul.-set. 2016. 